\title{
A Small-Scale Anatomic Model for Testicular Radiation Dosimetry for Radionuclides Localized in the Human Testes
}

\author{
Erik Larsson, Suaad A. Meerkhan, Sven-Erik Strand, and Bo-Anders Jönsson \\ Department of Medical Radiation Physics, Clinical Sciences, Lund University, Lund, Sweden
}

The testis is a radiosensitive tissue. It contains a large number of lobules, which in turn are composed of convoluted seminiferous tubules. The epithelium inside each tubule consists of a complex mosaic of supporting cells and germ cells of different sizes and degrees of maturation. These cells are known to have diverse sensitivity to radiation, those with the highest sensitivity being the spermatogonia, which form part of the basal cell layer, and those with the lowest sensitivity being the mature sperm cells closest to the lumen of the tubule. For many years, the internal dosimetry community has discussed the need for improvements to bring about more detailed, cell-level testicular dosimetry. This paper presents a small-scale dosimetry model for calculation of $S$ factors for several different source-target configurations within the testicular tissue. Methods: A model of the testis was designed in which the lobules were approximated by a cross-section of seminiferous tubules arranged in a hexagonal pattern, with interstitial tissue between them. The seminiferous tubules were divided into concentric layers representing spermatogenic development in the seminiferous epithelium. $S$ factors were calculated for electrons, photons,

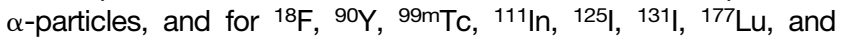
${ }^{211}$ At using Monte Carlo simulations. Results: For electrons with low energies the range was small, compared with the diameter of the seminiferous tubules, resulting in high energy deposition close to the source, whereas for higher electron energies more uniform energy deposition was seen, as expected. The same trend was seen for low-energy photons, whose mean free paths are small, compared with the diameter of the seminiferous tubules, resulting in high energy deposition close to the source, whereas for higher photon energies the location of the activity in the testis is less important. Conclusion: The model presented in this paper is a simplification of the organized chaos that constitutes the structure of the actual testis. However, it provides a relevant, small-scale anatomic model to help us understand the significance of the heterogeneity of radioactivity in this important radiosensitive tissue.

Key Words: testes; Monte Carlo; small-scale; dosimetry; $S$ factors

J Nucl Med 2012; 53:72-81

DOI: 10.2967/jnumed.111.095133

Received Jul. 1, 2011; revision accepted Sep. 6, 2011.

For correspondence or reprints contact: Erik Larsson, Department of Medical Radiation Physics, Clinical Sciences, Lund University, Skåne University Hospital, SE 22185 Lund, Sweden.

E-mail: erik.larsson@med.lu.se

Published online Nov. 11, 2011.

COPYRIGHT @ 2012 by the Society of Nuclear Medicine, Inc.
$\mathbf{I}$ well known that the testes are among the most radiosensitive tissue in the human body. They constitute an important critical target for both external and internal radiation during diagnostic and therapeutic use of radionuclides or after internal contamination resulting from occupational exposure or accidents. The metallic radionuclides, such as ${ }^{65} \mathrm{Zn},{ }^{111} \mathrm{In},{ }^{201} \mathrm{Tl}$, and ${ }^{239} \mathrm{Pu}$, are of special interest in radiation testicular dosimetry because they are known to gain access to the seminiferous tubules and the germ cells (1-4). Some ${ }^{90} \mathrm{Y}$ - and ${ }^{111}$ In-labeled radiopharmaceuticals have also been reported to be retained in the testes (5-7).

Uniform external irradiation at sufficiently high absorbed doses leads to deterministic damage to the testes and is quite well understood (8). The threshold absorbed dose for temporary sterility is only $0.15 \mathrm{~Gy}$ when received in a single acute exposure, whereas for permanent sterility it is 3.5-6.0 Gy. The annual dose rates causing temporary and permanent sterility from highly fractionated or protracted exposure over a period of years have been specified by the International Commission on Radiological Protection to be 0.4 and 2.0 Gy $\cdot y^{-1}$, respectively (9). Although the deterministic effects are well known, little is known about the occurrence of radiation-induced cancer in the testes (10), and so far there is no evidence that radiation-induced mutations in the germ cells cause genetic disease in humans (11). However, this possibility is considered in radiation protection and risk estimates by the International Commission on Radiological Protection, which has assigned a tissue weighting factor of 0.08 for the gonads (12). In addition, the accumulation of activity and long retention times in the testis may lead to depletion of the proliferating tissue, that is, permanent sterility.

The radiobiologic response of testicular cells undergoing spermatogenesis to ionizing radiation has been well established in the mouse and rat $(13-15)$ and is considered to be relevant to humans (16). Radiation damage and the death of germ cells can impair fertility in a dose-dependent way. Spermatogonia in the early stage of differentiation are much more sensitive to radiation than cells in the later stages of maturation, that is, primary and secondary spermatocytes, spermatids, and spermatozoa $(17,18)$.

The testes consist of 2 ovoid organs with a short axis of about $2.5 \mathrm{~cm}$ and a long axis of about $4 \mathrm{~cm}$ enclosed in a dense capsule of strong connective tissue, the tunica 
albuginea, which is about $0.8 \mathrm{~mm}$ thick (19). Published data on the mass and volume of the testes vary and depend on age and state of health. For the purpose of internal dosimetry or phantom modeling, the International Commission on Radiological Protection recommends an adult reference mass and volume for both testes of $35 \mathrm{~g}$ and $33 \mathrm{~cm}^{3}$, respectively, and a density of $1.04 \mathrm{~g} \cdot \mathrm{cm}^{-3}(20)$. Each testis is divided into 250-370 conical and intercommunicating compartments of varying size, called the testicular lobules. These lobules are occupied by $1-4$ seminiferous tubules, which are convoluted loops distributed throughout the testis. The total length of the tubules measures about $70-80 \mathrm{~cm}$, and their diameter varies from 150 to $300 \mu \mathrm{m}$ (19). The seminiferous tubules are surrounded by interstitial tissue, which contains blood and lymphatic vessels, nerves, tissue macrophages, and groups of endocrine Leydig cells, responsible for the secretion of testosterone. Spermatogenesis, that is, the complex process by which spermatogonial stem cells proliferate and transform into spermatozoa, with a period of $64 \mathrm{~d}$ in humans, takes place in the seminiferous tubules.

The basement membrane, or lamina propriae, of the seminiferous tubules is made up of 5-7 cellular layers separated by laminae of extracellular connective tissue components, with a total thickness of about $8 \mu \mathrm{m}$. Each tubule is lined with a seminiferous epithelium composed of columnar supporting cells called Sertoli cells and the germ cells of the spermatogenic lineage. Figure 1 illustrates the anatomy of the testis. The architectural arrangement of the seminiferous epithelium from the basement membrane starts with the radiosensitive germ cells, spermatogonia, 9-12 $\mu \mathrm{m}$ in diameter. These germ cells undergo mitosis and form either type $A_{S}$ spermatogonia stem cells or type $\mathrm{A}_{\mathrm{P}}$ spermatogonia progenitor cells, the latter dividing several times to finally form type B spermatogonia. On their inner side lie the primary spermatocytes, which are larger, 16-18 $\mu \mathrm{m}$, and arise from the type B spermatogonia by mitotic cell division. By maturation division, each primary spermatocyte then produces 2 secondary spermatocytes (prespermatids) that are slightly less than half the size of the mother cell, that is, 7-8 $\mu \mathrm{m}$. These divide quickly to become haploid spermatids, differentiating into mature sperm cells that are released into the lumen of the tubule. The spermatozoa secreted by the seminiferous tubules are collected in the rete testis and delivered to the excurrent ductal system of the epididymis (21).

The germ cells in the seminiferous epithelium are closely associated with and almost completely surrounded by the surface of the columnar Sertoli cells. These latter cells protect the germ cells from autoimmune attacks and toxic and radioactive foreign agents by the so-called blood-testis barrier $(19,21)$. Only the stem cells, type A spermatogonia, closest to the basement membrane may have direct contact with the extracellular environment. Radionuclides and radiolabeled molecules such as peptides and antibodies entering the human body by internal contamination or after administration of a radiopharmaceutical for diagnostic or therapeutic purposes may localize in the testes (1-7). Studies in rodents have shown that indium isotopes accumulate in the interstitial tissue and the seminiferous epithelium after intravenous administration. Like iron, indium isotopes are transported into germ cells inside the blood-testis barrier by a mechanism involving the specific transport protein transferrin (3,4,22-24). In multilevel autoradiographic investigations by Jönsson et al., it was demonstrated that an intravenous administration of ${ }^{111} \mathrm{In}$-chloride resulted in a highly heterogeneous distribution in the proliferating tissues, including the testes (Fig. 2A) $(3,25,26)$. It was shown that the uptake in rat testes was mainly localized not only in the interstitial tissue, but also in the spermatogonia, with an activity uptake far above the background level (Fig. 2B). Hoyes et al. demonstrated that intratesticular localization results in spermatogenic and mutagenic damage (27).

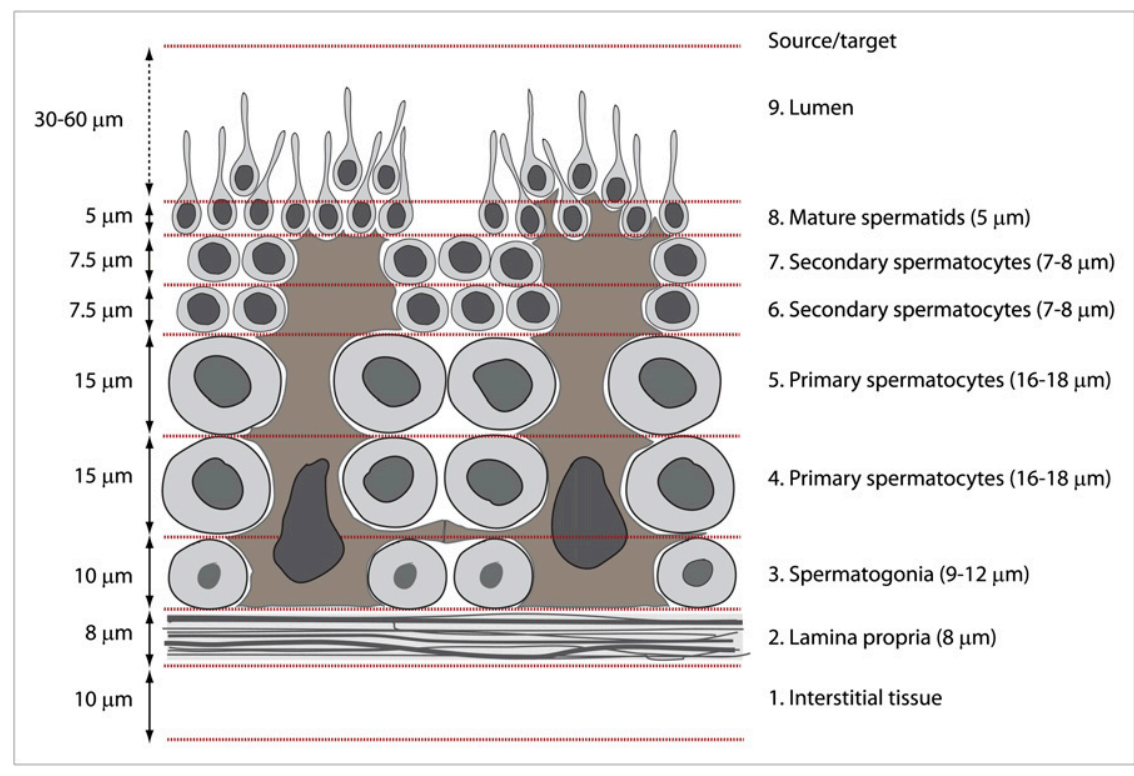

FIGURE 1. Outline of seminiferous tubule, showing multiple layers representing different kinds of germ cells involved in spermatogenesis. 

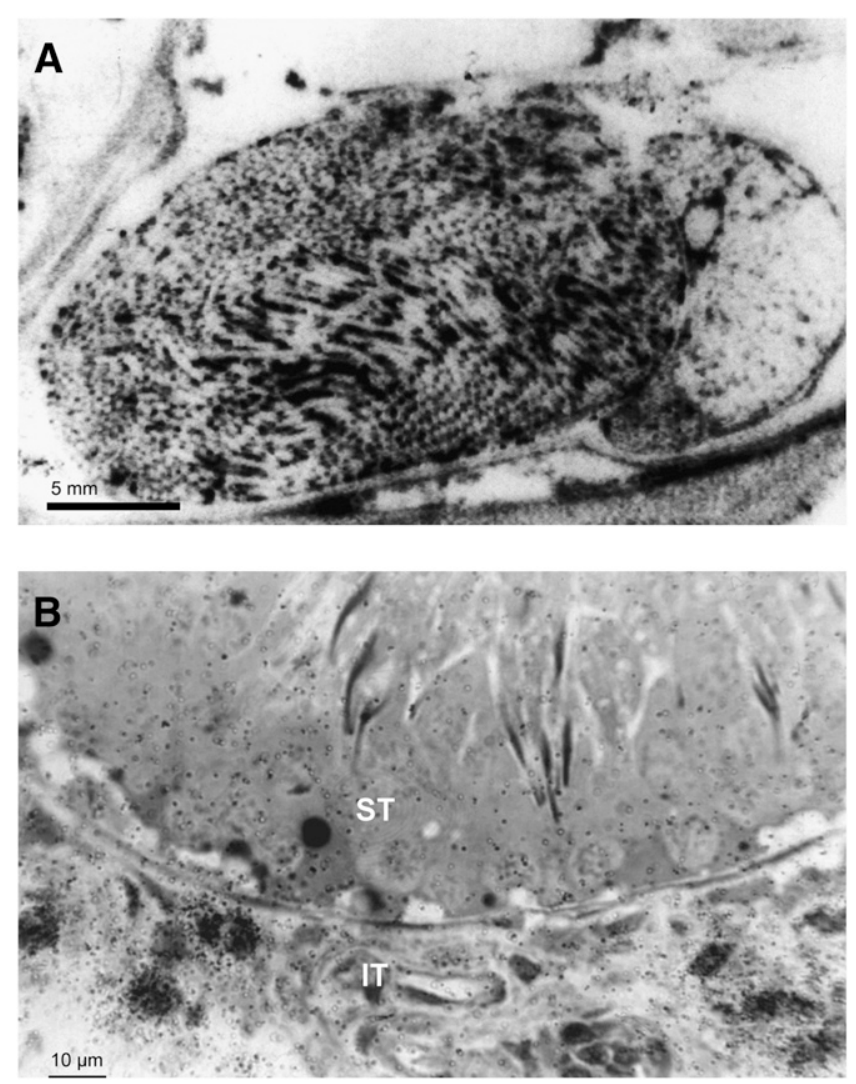

FIGURE 2. (A) Sagittal cross-section of a macro-autoradiograph showing heterogeneous activity distribution (dark patches) in rat testis $5 \mathrm{~d}$ after injection of ${ }^{111} \mathrm{In}$. (B) Light microscopy autoradiograph showing localization of indium (dark dots) in interstitial tissue (IT) and seminiferous tubule (ST), with spermatogonial cells closest to basement membrane. Significant amount of activity can be seen in interstitial tissue, with specific concentration in macrophages. Activity present in layer of spermatogonial cells closest to basal lamina is also notable $(3,25)$.

Published data on radioactivity in the human testes are scarce, but in a study by Nettleton et al. it was shown that after intravenous injection in male patients the radiometals ${ }^{111} \mathrm{In}$ and ${ }^{201} \mathrm{Tl}$ were localized in the testes (4). The uptake was about 3.6- to 4.0-fold higher than the nonspecific uptake in the remainder of the body. It was concluded that the radionuclides crossed the blood-testis barrier and gained access to the developing germ cells within the seminiferous epithelium. Nuclear medicine studies during the late 1980s using ${ }^{111}$ In-labeled anti-carcinoembryonic antigen monoclonal antibodies and $\mathrm{F}\left(\mathrm{ab}^{\prime}\right) 2$ fragments for scintigraphy of colon cancer showed that male patients had an unexpectedly high activity uptake in the testes $(28,29)$. During the past decade, several authors have reported testicular uptake in patients after administration of ${ }^{111} \mathrm{In}$ - or ${ }^{90}$ Y-labeled antibodies, such as the radionuclide-antibody conjugate ibritumomab tiuxetan (Zevalin; Biogen Idec Inc.) commonly used for radionuclide therapy $(5-7,30)$. The mean absorbed doses to testis reported in these studies varied from 2.4 to $9.1 \mathrm{~Gy} \cdot \mathrm{GBq}^{-1}$, that is, above the threshold for sterility. Caution is thus advised in the treatment of young male patients, and semen cryopreservation may be appropriate, according to the European Association of Nuclear Medicine guidelines (31).

Investigations of testicular uptake of radioactivity, especially those showing a heterogeneous distribution, have attracted much attention from the dosimetry community $(32,33)$. In this context, the primary objective of this investigation was to develop a realistic, small-scale anatomic model of the seminiferous epithelium and to determine $\mathrm{S}$ factors $(34,35)$, or so-called dose conversion factors, for different source-target combinations in the testicular tissue.

\section{MATERIALS AND METHODS}

The small-scale anatomic model of the testes developed in this study consists of an ellipsoid with axes of $2.5,2.5$, and $4.0 \mathrm{~cm}$. The mosaic pattern of the complex structure of the testicular lobules was approximated by a cross-section of seminiferous tubules, $250 \mu \mathrm{m}$ wide, arranged $10 \mu \mathrm{m}$ apart in a hexagonal pattern, with interstitial tissue between them (Fig. 3). Each seminiferous tubule was then divided into concentric layers, as described in Figure 1, starting from the basement membrane, that is, the lamina propria $(8 \mu \mathrm{m})$ of the seminiferous tubule. The layers correspond to the most plausible loci of different germ cells during their spermatogenetic development in the seminiferous epithelium, that is, 1 layer of spermatogonia $(10 \mu \mathrm{m}), 2$ layers of primary spermatocytes (15 $\mu \mathrm{m}), 2$ layers of secondary spermatocytes $(7.5 \mu \mathrm{m}), 1$ layer corre-
FIGURE 3. (A) Cross-section of testicular geometry approximated by hexagonal pattern of $250-\mu \mathrm{m}$-diameter cylinders representing seminiferous tubules. The $10-\mu \mathrm{m}$ space between seminiferous tubules was assumed to be filled with interstitial tissue. (B) Each seminiferous tubule was divided into 9 layers starting at basement membrane and extending toward lumen.

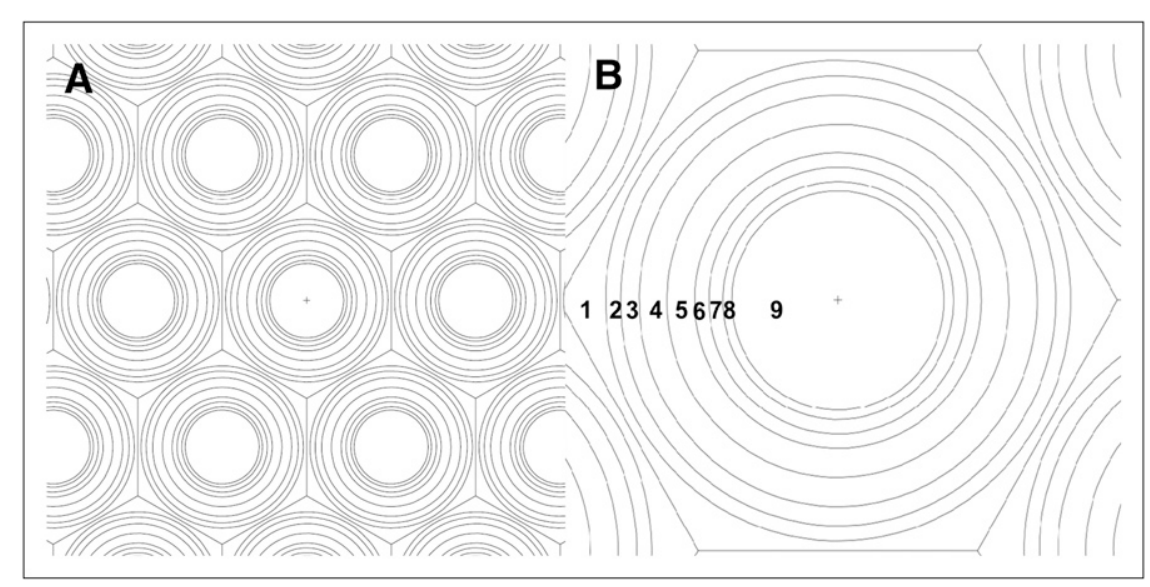


sponding to mature spermatids $(5 \mu \mathrm{m})$, and, finally, spermatozoa in the lumen $(57 \mu \mathrm{m})$ of the seminiferous tubule.

The Monte Carlo codes MCNP5 1.4 (36) and MCNPX 2.6 (37) were used to model this testis geometry. The close-packed structure of the seminiferous tubules was simulated with a hexagonal lattice pattern (featured in MCNP by "lat = 2"), with an inscribed diameter of $260 \mu \mathrm{m}$, where the extra $10 \mu \mathrm{m}$ constitute interstitial tissue. Each lattice element was filled with concentric cylinders with radii of 57, $62,69.5,77,92,107,117$, and $125 \mu \mathrm{m}$, representing the different layers of the seminiferous tubule (Figs. 1 and 3B). The mass density was set to $1.04 \mathrm{~g} \cdot \mathrm{cm}^{-3}$, and the material composition for testis was taken from publication 89 of the International Commission on Radiological Protection (20). The total mass of the testes was then $13.6 \mathrm{~g}$.

The absorbed fractions were calculated for monoenergetic electrons, photons, and $\alpha$-particles using different source configurations. The energies used for monoenergetic electrons were 5 , $10,30,50,70,100,200,300,500$, and 1,000 keV; the energies used for monoenergetic photons were 5, 10, 15, 20, 30, 40, 50, 70, 100 , and $200 \mathrm{keV}$, and the energies used for monoenergetic $\alpha$-particles were $3,4,5,6,7$, and $8 \mathrm{MeV}$. In addition, Monte Carlo simulations of the $\mathrm{S}$ factors were performed for the radionuclides ${ }^{18} \mathrm{~F},{ }^{90} \mathrm{Y},{ }^{99 \mathrm{~m}} \mathrm{Tc},{ }^{111} \mathrm{In},{ }^{125} \mathrm{I},{ }^{131} \mathrm{I},{ }^{177} \mathrm{Lu}$, and ${ }^{211} \mathrm{At}$, as these are important in nuclear medicine. For ${ }^{211} \mathrm{At}$, the daughter product ${ }^{211}$ Po was included in the simulations because of the short halflife of $0.52 \mathrm{~s}$. The energies and yields were obtained using the software Radiation Decay 3 (Charles Hacker, Griffith University), which is based on data from the Radiation Shielding Information Center at Oak Ridge National Laboratories. The $\beta$-spectra used were obtained from the RADAR Web site (38).

The source of activity (and thus the emitted energy) was assumed to be homogeneously distributed within the interstitial tissue (region 1) or cell layer (regions 2-9) 1 source region at a time. Simulations that included sources consisting of photons, electrons, $\alpha$-particles, and $\beta$-particles were performed separately. The energy deposition from each source region was simulated separately using the energy deposition tally, specified as *f8 in the input files. Electron transport was simulated using the new energy-straggling logic introduced with MCNP5 1.4 and specified by the card dbcn $17 \mathrm{j} 2$. The number of substeps was set to 50 for all layers except 1 and 2 shown in Figure 1. The number of substeps for these layers and cells was set to 10, because a limitation in the MCNP code can cause particles to "get lost" in the boundaries between hexagonal lattices. This new logic allows more accurate simulation of electrons in small regions. When either of the 2 previous energy indexing methods, MCNP-style (default) or ITS-style ( $\mathrm{dbcn} 17 \mathrm{j} 1$ ), is used, the many boundaries in the geometry introduce errors in the energy straggling, resulting in overestimation of the energy deposition and shortening of the electron range. Because MCNP5 1.4 allows for the simulation of only neutrons, photons, electrons, and positrons, the Monte Carlo code MCNPX 2.6 was used in the simulation of $\alpha$-particles. However, this code does not include the new energy logic for electrons;
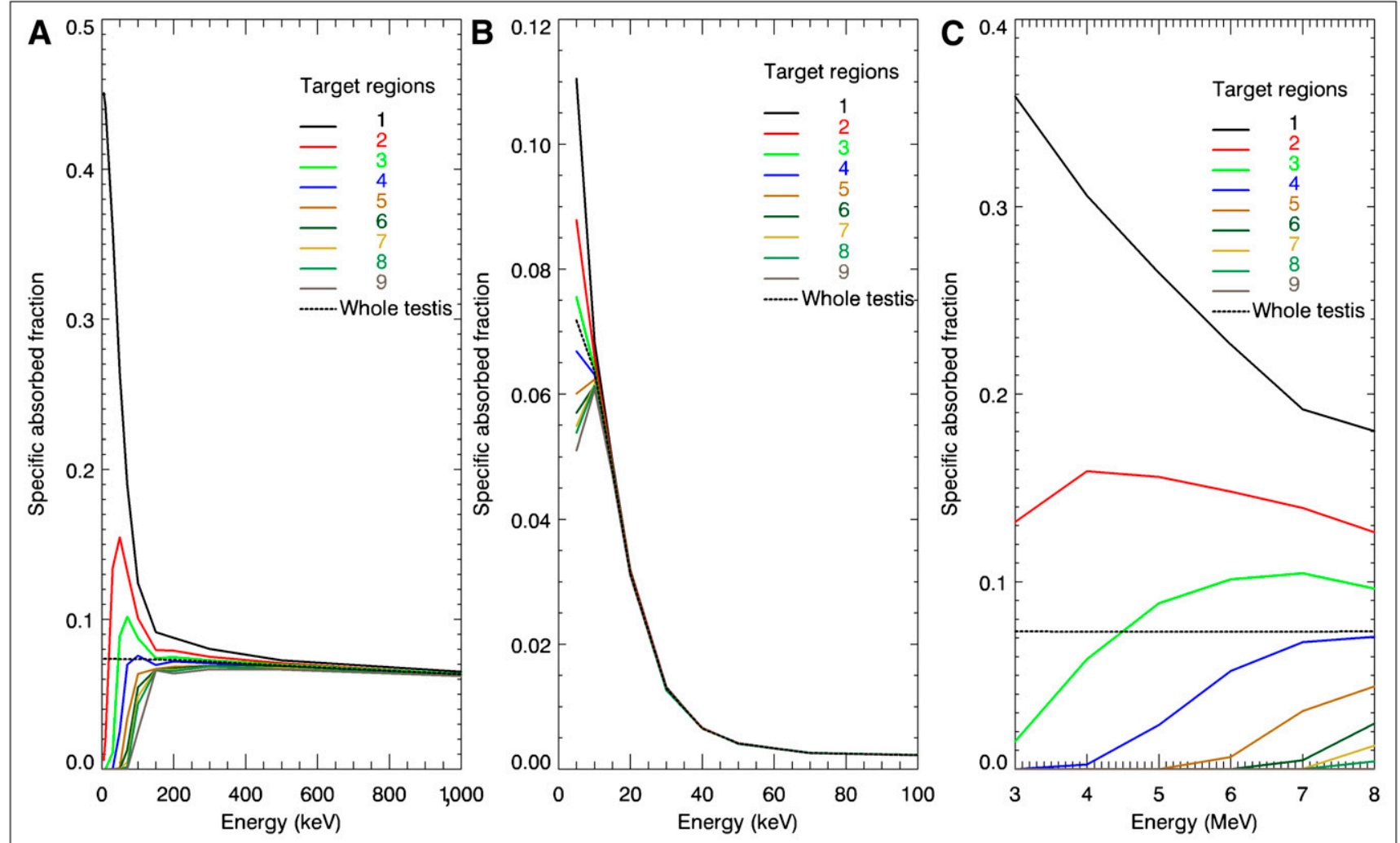

FIGURE 4. Specific absorbed fraction in different cell layers when source is located in interstitial tissue (region 1). Dashed line represents whole-testis specific absorbed fraction. (A) Low-energy electrons and short ranges have widest diversion from whole-testis specific absorbed fraction, whereas high-energy electrons converge toward average whole-testis specific absorbed fraction. (B) For photon energies above $15 \mathrm{keV}$, specific absorbed fraction is independent of source location; between 70 and $200 \mathrm{keV}$, specific absorbed fraction is almost independent of energy. (C) Specific absorbed fraction for $\alpha$-particles diverges markedly from whole-testis specific absorbed fraction because of the short ranges. 
therefore, its use was restricted to simulation of $\alpha$-particles. After the simulations, the results obtained from the different starting particle types were added together considering the radiation yield, and tables of absorbed fractions and $\mathrm{S}$ factors were calculated. The total number of simulated histories was on the order of $10^{6}$ to keep the statistical errors below $1 \%$. In the case of low electron energies, where the only dose contributions were due to bremsstrahlung photons, higher uncertainties were accepted, as the absolute values are negligible.

\section{RESULTS}

Figure 4 shows the specific absorbed fraction for each target region when the activity is in region 1 (interstitial tissue) for electrons, photons, and $\alpha$-particles. For lowenergy electrons the range is small, compared with the diameter of the seminiferous tubules, resulting in energy deposition close to the source. For electrons with higher energies, the energy is deposited over several loops of the tubule, resulting in a more uniform energy deposition. A behavior similar to that for low-energy electrons exists for the $\alpha$-particles, having ranges between 17 and $75 \mu \mathrm{m}$. Even though these ranges can appear as long as in the testis model, the direction of the emission matters. Particles emitted along the cylinder-surface normal vectors are rare, causing most of the energy to be deposited in the source and the nearest adjacent layer.

If the activity is assumed to be distributed outside the seminiferous tubule in the interstitial tissue (region 1), the absorbed dose to the radiosensitive spermatogonia (region 3) resulting from $30-\mathrm{keV}$ electrons is 6.0 times lower than if the source is assumed to be homogeneously distributed
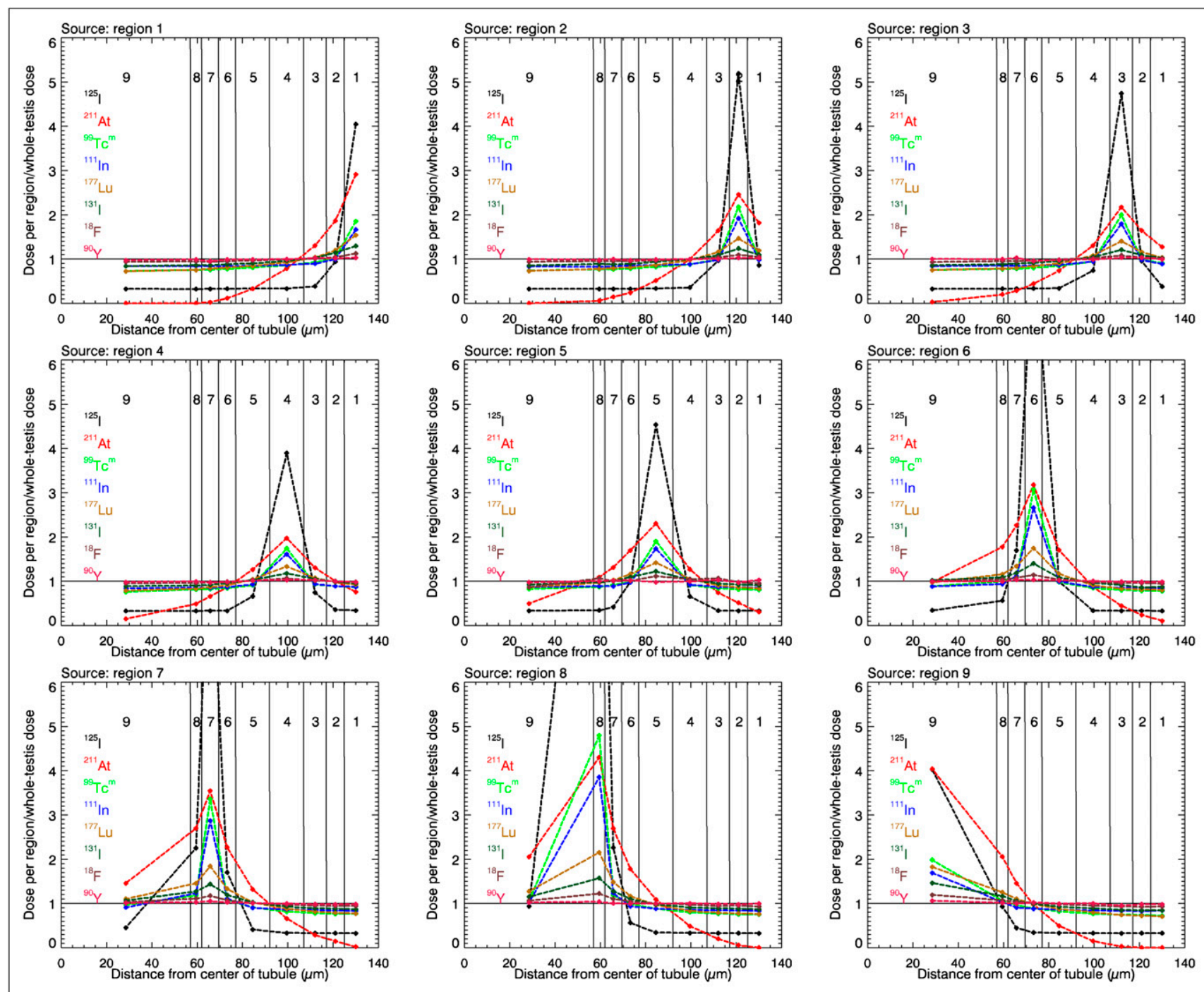

FIGURE 5. Graphs showing ratio of absorbed dose to each region of testis to average whole-testis absorbed dose for activity homogeneously distributed in the 9 regions. Horizontal solid line in each graph at ordinate value of 1 corresponds to average absorbed dose to whole testis. Symbols denote average absorbed dose within each region, with line segments drawn between successive data points simply providing visual guidance. Range of $y$-axis was selected to maximize visual appearance in layers closest to spermatogonia, causing ${ }^{125}$ in region 6,7 , and 8 to be out of the scale. 
TABLE 1

$S$ factors (mGy/MBq) for ${ }^{18} \mathrm{~F}$

\begin{tabular}{|c|c|c|c|c|c|c|c|c|c|}
\hline \multirow[b]{2}{*}{ Target } & \multicolumn{9}{|c|}{ Source } \\
\hline & 1 & 2 & 3 & 4 & 5 & 6 & 7 & 8 & 9 \\
\hline 1 & 0.00360 & 0.00338 & 0.00325 & 0.00314 & 0.00305 & 0.00304 & 0.00302 & 0.00298 & 0.00298 \\
\hline 2 & 0.00334 & 0.00350 & 0.00333 & 0.00321 & 0.00314 & 0.00306 & 0.00302 & 0.00305 & 0.00297 \\
\hline 3 & 0.00322 & 0.00334 & 0.00346 & 0.00324 & 0.00343 & 0.00308 & 0.00305 & 0.00302 & 0.00299 \\
\hline 4 & 0.00315 & 0.00320 & 0.00327 & 0.00342 & 0.00335 & 0.00315 & 0.00311 & 0.00312 & 0.00305 \\
\hline 5 & 0.00310 & 0.00309 & 0.00315 & 0.00324 & 0.00357 & 0.00332 & 0.00324 & 0.00322 & 0.00313 \\
\hline 6 & 0.00305 & 0.00306 & 0.00308 & 0.00316 & 0.00325 & 0.00366 & 0.00344 & 0.00334 & 0.00325 \\
\hline 7 & 0.00301 & 0.00306 & 0.00306 & 0.00313 & 0.00320 & 0.00346 & 0.00376 & 0.00353 & 0.00332 \\
\hline 8 & 0.00303 & 0.00305 & 0.00305 & 0.00308 & 0.00343 & 0.00334 & 0.00356 & 0.00392 & 0.00344 \\
\hline 9 & 0.00300 & 0.00301 & 0.00299 & 0.00305 & 0.00277 & 0.00322 & 0.00330 & 0.00342 & 0.00382 \\
\hline
\end{tabular}

TABLE 2

$S$ factors (mGy/MBq) for ${ }^{90} \mathrm{Y}$

\begin{tabular}{lccccccccc}
\hline & \multicolumn{9}{c}{ Source } \\
\cline { 2 - 8 } Target & 1 & 2 & 3 & 4 & 5 & 6 & 7 & 8 & 9 \\
\hline 1 & 0.00949 & 0.00935 & 0.00933 & 0.00910 & 0.00954 & 0.00914 & 0.00919 & 0.00922 & 0.00918 \\
2 & 0.00940 & 0.00945 & 0.00967 & 0.00925 & 0.00901 & 0.00911 & 0.00917 & 0.00908 & 0.00922 \\
3 & 0.00946 & 0.00918 & 0.00971 & 0.00956 & 0.00955 & 0.00916 & 0.00919 & 0.00915 & 0.00895 \\
4 & 0.00920 & 0.00915 & 0.00931 & 0.00955 & 0.00926 & 0.00929 & 0.00934 & 0.00926 & 0.00939 \\
5 & 0.00913 & 0.00909 & 0.00919 & 0.00947 & 0.00909 & 0.00946 & 0.00943 & 0.00922 & 0.00932 \\
6 & 0.00912 & 0.00893 & 0.00896 & 0.00914 & 0.00950 & 0.00958 & 0.00961 & 0.00922 & 0.00960 \\
7 & 0.00881 & 0.00917 & 0.00968 & 0.00903 & 0.00940 & 0.00958 & 0.00987 & 0.00929 & 0.00932 \\
8 & 0.00914 & 0.00898 & 0.00937 & 0.00922 & 0.00928 & 0.00923 & 0.00962 & 0.00962 & 0.00953 \\
9 & 0.00897 & 0.00911 & 0.00939 & 0.00909 & 0.00905 & 0.00921 & 0.00944 & 0.00948 & 0.00997 \\
& & & & & & & & &
\end{tabular}

Target and source numbers correspond to different cell layers of testis model as described in Figure 1.

TABLE 3

$S$ factors (mGy/MBq) for ${ }^{99 m T c}$

\begin{tabular}{|c|c|c|c|c|c|c|c|c|c|}
\hline \multirow[b]{2}{*}{ Target } & \multicolumn{9}{|c|}{ Source } \\
\hline & 1 & 2 & 3 & 4 & 5 & 6 & 7 & 8 & 9 \\
\hline 1 & 0.000437 & 0.000236 & 0.000215 & 0.000204 & 0.000191 & 0.000184 & 0.000181 & 0.000179 & 0.000170 \\
\hline 2 & 0.000241 & 0.000513 & 0.000232 & 0.000209 & 0.000193 & 0.000186 & 0.000181 & 0.000179 & 0.000173 \\
\hline 3 & 0.000219 & 0.000233 & 0.000472 & 0.000219 & 0.000197 & 0.000190 & 0.000184 & 0.000183 & 0.000175 \\
\hline 4 & 0.000203 & 0.000207 & 0.000222 & 0.000409 & 0.000216 & 0.000200 & 0.000193 & 0.000190 & 0.000181 \\
\hline 5 & 0.000191 & 0.000194 & 0.000199 & 0.000214 & 0.000449 & 0.000233 & 0.000214 & 0.000210 & 0.000194 \\
\hline 6 & 0.000184 & 0.000185 & 0.000189 & 0.000198 & 0.000232 & 0.000728 & 0.000257 & 0.000234 & 0.000208 \\
\hline 7 & 0.000180 & 0.000181 & 0.000185 & 0.000194 & 0.000217 & 0.000260 & 0.000793 & 0.000281 & 0.000225 \\
\hline 8 & 0.000177 & 0.000181 & 0.000182 & 0.000192 & 0.000206 & 0.000235 & 0.000278 & 0.001137 & 0.000249 \\
\hline 9 & 0.000171 & 0.000174 & 0.000177 & 0.000178 & 0.000195 & 0.000211 & 0.000228 & 0.000250 & 0.000466 \\
\hline
\end{tabular}

Target and source numbers correspond to different cell layers of testis model as described in Figure 1.

throughout the whole testis. For $70-\mathrm{keV}$ electrons, the corresponding absorbed dose would be 1.4 times higher than the whole-testis absorbed dose.

If the activity is instead located in the spermatogonia (region 3), the calculated absorbed dose to this region, compared with the average absorbed dose in whole testis, is 4.9 times higher for $30-\mathrm{keV}$ electrons and 1.9 times higher for $70-\mathrm{keV}$ electrons.

For low-energy photons, the mean free path is small, compared with the diameter of the seminiferous tubules, 
TABLE 4

$S$ factors (mGy/MBq) for ${ }^{111} \mathrm{In}$

\begin{tabular}{lccccccccc}
\hline & \multicolumn{9}{c}{ Source } \\
\cline { 2 - 8 } Target & 1 & 2 & 3 & 4 & 5 & 6 & 7 & 8 & 9 \\
\hline 1 & 0.001021 & 0.000600 & 0.000545 & 0.000532 & 0.000523 & 0.000512 & 0.000511 & 0.000511 & 0.000510 \\
2 & 0.000610 & 0.001172 & 0.000601 & 0.000542 & 0.000528 & 0.000518 & 0.000515 & 0.000516 & 0.000501 \\
3 & 0.000550 & 0.000601 & 0.001097 & 0.000573 & 0.000533 & 0.000523 & 0.000522 & 0.000520 & 0.000507 \\
4 & 0.000530 & 0.000539 & 0.000577 & 0.000982 & 0.000565 & 0.000534 & 0.000528 & 0.000523 & 0.000509 \\
5 & 0.000518 & 0.000523 & 0.000529 & 0.000567 & 0.001065 & 0.000609 & 0.000551 & 0.000543 & 0.000521 \\
6 & 0.000515 & 0.000521 & 0.000523 & 0.000527 & 0.000599 & 0.001632 & 0.000679 & 0.000575 & 0.000534 \\
7 & 0.000512 & 0.000508 & 0.000517 & 0.000519 & 0.000544 & 0.000686 & 0.001759 & 0.000757 & 0.000553 \\
8 & 0.000515 & 0.000505 & 0.000519 & 0.000520 & 0.000546 & 0.000575 & 0.000753 & 0.002372 & 0.000624 \\
9 & 0.000515 & 0.000507 & 0.000512 & 0.000511 & 0.000531 & 0.000542 & 0.000559 & 0.000625 & 0.001028 \\
& & & & & & & & & \\
\hline
\end{tabular}

Target and source numbers correspond to different cell layers of testis model as described in Figure 1.

TABLE 5

$S$ factors (mGy/MBq) for ${ }^{125}$

\begin{tabular}{lccccccccc}
\hline & \multicolumn{7}{c}{ Source } \\
\cline { 2 - 8 } Target & 1 & 2 & 3 & 4 & 5 & 6 & 7 & 8 & 9 \\
\hline 1 & 0.001242 & 0.000262 & 0.000116 & 0.000103 & 0.000101 & 0.000101 & 0.000100 & 0.000100 & 0.000101 \\
2 & 0.000288 & 0.001589 & 0.000294 & 0.000109 & 0.000102 & 0.000102 & 0.000101 & 0.000101 & 0.000100 \\
3 & 0.000118 & 0.000295 & 0.001454 & 0.000228 & 0.000103 & 0.000102 & 0.000101 & 0.000100 & 0.000100 \\
4 & 0.000102 & 0.000109 & 0.000227 & 0.001193 & 0.000201 & 0.000103 & 0.000102 & 0.000102 & 0.000100 \\
5 & 0.000102 & 0.000103 & 0.000104 & 0.000201 & 0.001391 & 0.000306 & 0.000126 & 0.000105 & 0.000102 \\
6 & 0.000100 & 0.000100 & 0.000103 & 0.000102 & 0.000304 & 0.002680 & 0.000522 & 0.000173 & 0.000105 \\
7 & 0.000099 & 0.000100 & 0.000102 & 0.000101 & 0.000128 & 0.000521 & 0.002973 & 0.000695 & 0.000137 \\
8 & 0.000099 & 0.000099 & 0.000101 & 0.000101 & 0.000105 & 0.000173 & 0.000690 & 0.004408 & 0.000285 \\
9 & 0.000100 & 0.000100 & 0.000100 & 0.000101 & 0.000102 & 0.000105 & 0.000139 & 0.000287 & 0.001233 \\
\hline
\end{tabular}

Target and source numbers correspond to different cell layers of testis model as described in Figure 1.

TABLE 6

$S$ factors (mGy/MBq) for ${ }^{131}$

\begin{tabular}{lccccccccc}
\hline & \multicolumn{9}{c}{ Source } \\
\cline { 2 - 8 } Target & 1 & 2 & 3 & 4 & 5 & 6 & 7 & 8 & 9 \\
\hline 1 & 0.00324 & 0.00275 & 0.00256 & 0.00239 & 0.00228 & 0.00219 & 0.00219 & 0.00216 & 0.00211 \\
2 & 0.00286 & 0.00311 & 0.00273 & 0.00247 & 0.00232 & 0.00217 & 0.00222 & 0.00219 & 0.00211 \\
3 & 0.00257 & 0.00273 & 0.00303 & 0.00263 & 0.00238 & 0.00230 & 0.00224 & 0.00222 & 0.00213 \\
4 & 0.00240 & 0.00250 & 0.00262 & 0.00294 & 0.00259 & 0.00242 & 0.00234 & 0.00227 & 0.00221 \\
5 & 0.00227 & 0.00235 & 0.00238 & 0.00257 & 0.00307 & 0.00272 & 0.00258 & 0.00244 & 0.00230 \\
6 & 0.00220 & 0.00223 & 0.00229 & 0.00240 & 0.00274 & 0.00352 & 0.00300 & 0.00274 & 0.00249 \\
7 & 0.00216 & 0.00222 & 0.00224 & 0.00230 & 0.00254 & 0.00299 & 0.00361 & 0.00318 & 0.00264 \\
8 & 0.00216 & 0.00222 & 0.00221 & 0.00226 & 0.00246 & 0.00274 & 0.00320 & 0.00392 & 0.00291 \\
9 & 0.00211 & 0.00213 & 0.00215 & 0.00222 & 0.00232 & 0.00257 & 0.00268 & 0.00286 & 0.00366 \\
& & & & & & & & \\
\hline
\end{tabular}

Target and source numbers correspond to different cell layers of testis model as described in Figure 1.

resulting in energy deposition close to the source. For photon energies higher than about $10 \mathrm{keV}$, the emitted energy is deposited over many tubules, resulting in more uniform energy deposition. For example, assuming 5-keV photons to be distributed homogenously in the interstitial tissue (region 1) or in the spermatogonia (region 3), the absorbed dose to the spermatogonia compared with the average whole-testis dose is a factor of 1.05 and 1.39 higher, respectively. For higher photon energies, the energy deposition is more uniform, and the location of the source 
TABLE 7

$S$ factors (mGy/MBq) for ${ }^{177} \mathrm{Lu}$

\begin{tabular}{lccccccccc}
\hline & \multicolumn{7}{c}{ Source } \\
\cline { 2 - 8 } Target & 1 & 2 & 3 & 4 & 5 & 6 & 7 & 8 & 9 \\
\hline 1 & 0.00282 & 0.00219 & 0.00190 & 0.00170 & 0.00154 & 0.00145 & 0.00143 & 0.00139 & 0.00129 \\
2 & 0.00220 & 0.00269 & 0.00212 & 0.00179 & 0.00159 & 0.00148 & 0.00146 & 0.00142 & 0.00133 \\
3 & 0.00191 & 0.00213 & 0.00258 & 0.00197 & 0.00167 & 0.00152 & 0.00150 & 0.00145 & 0.00136 \\
4 & 0.00170 & 0.00179 & 0.00198 & 0.00245 & 0.00193 & 0.00166 & 0.00162 & 0.00153 & 0.00147 \\
5 & 0.00155 & 0.00158 & 0.00166 & 0.00191 & 0.00260 & 0.00212 & 0.00190 & 0.00177 & 0.00160 \\
6 & 0.00148 & 0.00149 & 0.00155 & 0.00167 & 0.00213 & 0.00317 & 0.00246 & 0.00213 & 0.00182 \\
7 & 0.00143 & 0.00145 & 0.00147 & 0.00159 & 0.00188 & 0.00244 & 0.00340 & 0.00272 & 0.00202 \\
8 & 0.00138 & 0.00142 & 0.00144 & 0.00153 & 0.00178 & 0.00210 & 0.00269 & 0.00395 & 0.00230 \\
9 & 0.00132 & 0.00134 & 0.00138 & 0.00145 & 0.00159 & 0.00177 & 0.00204 & 0.00234 & 0.00335
\end{tabular}

Target and source numbers correspond to different cell layers of testis model as described in Figure 1.

in the testes is of less importance. For photons with energies of $70-200 \mathrm{keV}$, the specific absorbed fraction is almost independent of the energy.

Figure 5 shows the ratio of the absorbed dose in each region to the average absorbed dose in the whole testis among the radionuclides studied, and the absorbed dose when the activity is located either in the interstitial tissue outside the tubule (region 1) or in the different cell layers of the tubule (regions 2-9). Values close to 1 indicate small differences between the average absorbed dose to testes and the doses to the different target regions in the model. Radionuclides, such as ${ }^{90} \mathrm{Y}$ and ${ }^{18} \mathrm{~F}$, which emit higher-energy electrons and positrons having ranges that are long relative to the dimension of the seminiferous tubules have ratios close to 1 . For ${ }^{99 \mathrm{~m}} \mathrm{Tc},{ }^{111} \mathrm{In}$, and ${ }^{177} \mathrm{Lu}$, the local absorbed dose arises mainly from intermediate-range conversion electrons having energies between 100 and $250 \mathrm{keV}$ and are highest in the source layer itself, decreasing to doses equal to the respective average-testis doses in the immediately adjacent layers and beyond. ${ }^{131} \mathrm{I}$ is a medium-energy $\beta$-emitting radionuclide, with its major $\beta$-decay having a maximal energy of $606 \mathrm{keV}$, and is therefore situated in
Figure 5 between the curves of ${ }^{177} \mathrm{Lu}$ and ${ }^{18} \mathrm{~F}$. For ${ }^{211} \mathrm{At}$ and ${ }^{125} \mathrm{I}$, emitting short-range $\alpha$-particles and low-energy electrons, respectively, the doses to the source and immediately adjacent layer are highest, decreasing to less than the respective average whole-testis doses for those layers farther from the source. The simulated $\mathrm{S}$ factors for the radionuclides studied are given in Tables $1-8$.

\section{DISCUSSION}

In contrast to external radiation, the biologic effects of tissue-incorporated radionuclides are highly dependent on the type of radiation and on their distribution at macroscopic, microscopic, and cellular levels. In addition, this distribution is determined by the chemical characteristics of the radioactive agent. Because the biologic effects are expressed at the cellular level, much attention has been directed during recent years toward the development of small-scale anatomic models, taking the nonuniform activity distribution into consideration $(32,33,39)$. The wide variability in absorbed energy or absorbed dose to different parts of the tissue is of greater relevance than the average absorbed dose estimated by the conventional (i.e., organ-

TABLE 8

S factors (mGy/MBq) for ${ }^{211}$ At (Daughter Nuclide ${ }^{211}$ Po [0.52-Second Half-Life] Included)

\begin{tabular}{|c|c|c|c|c|c|c|c|c|c|}
\hline \multirow[b]{2}{*}{ Target } & \multicolumn{9}{|c|}{ Source } \\
\hline & 1 & 2 & 3 & 4 & 5 & 6 & 7 & 8 & 9 \\
\hline 1 & 0.23273 & 0.14514 & 0.10169 & 0.06072 & 0.02462 & 0.00849 & 0.00196 & 0.00006 & 0.00004 \\
\hline 2 & 0.14886 & 0.19628 & 0.13134 & 0.07995 & 0.04116 & 0.01906 & 0.01175 & 0.00473 & 0.00015 \\
\hline 3 & 0.10431 & 0.13134 & 0.17369 & 0.10449 & 0.05907 & 0.03556 & 0.02285 & 0.01617 & 0.00251 \\
\hline 4 & 0.06295 & 0.07976 & 0.10435 & 0.15765 & 0.10135 & 0.06917 & 0.05266 & 0.03893 & 0.01211 \\
\hline 5 & 0.02612 & 0.04114 & 0.05889 & 0.10108 & 0.18428 & 0.13632 & 0.10537 & 0.08738 & 0.03967 \\
\hline 6 & 0.00934 & 0.01911 & 0.03546 & 0.06935 & 0.13573 & 0.25417 & 0.18150 & 0.14224 & 0.07772 \\
\hline 7 & 0.00224 & 0.01171 & 0.02275 & 0.05281 & 0.10490 & 0.18106 & 0.28342 & 0.21538 & 0.11634 \\
\hline 8 & 0.00006 & 0.00467 & 0.01602 & 0.03912 & 0.08728 & 0.14202 & 0.21567 & 0.34384 & 0.16428 \\
\hline 9 & 0.00004 & 0.00015 & 0.00249 & 0.01210 & 0.03969 & 0.07782 & 0.11630 & 0.16398 & 0.32273 \\
\hline
\end{tabular}

Target and source numbers correspond to different cell layers of testis model as described in Figure 1. 
level) implementation of the MIRD formalism (34) and organ-level S factors. The microscopic anatomic model of the human testes presented in this paper has been used to derive the necessary reference data (i.e., $\mathrm{S}$ factors) for small-scale testicular dosimetry for selected radionuclides. Ultimately, more reliable dose-response relationships for the radiobiologic effects of radionuclides on germ-cell function should result. Although the model is a simplification of the complicated nature of the seminiferous epithelium, it provides a realistic approach for more detailed dosimetry while still using the MIRD formalism.

From these simulations, it is obvious that the absorbed energy in the layer corresponding to the radiosensitive spermatogonia may be underestimated or overestimated using the traditional method of calculating the absorbed dose to testis, that is, the average of the whole testis. The greatest divergences for both electrons and photons are found at the lower energies, since the energy is deposited in the vicinity of the source. For electron energies above $200 \mathrm{keV}$ and photon energies above $10 \mathrm{keV}$, the absorbed energy is averaged over several tubules, and the site of decay is therefore less important. Of the radionuclides studied here, this factor is most evident for ${ }^{125} \mathrm{I}$, because of its low conversion electron energies (27-32 keV), as can be seen in Figure 5. If activity is incorporated into the spermatogonia cell layer, the absorbed dose from ${ }^{125}$ I will be 4.74 times higher than the standard whole-testis absorbed dose, whereas if the activity is in the interstitial tissue, the absorbed dose will be 0.39 times the whole-testis absorbed dose. The energy from high-energy $\beta$-particles from the decay of ${ }^{90} \mathrm{Y}$ is deposited along an average path length of $3 \mathrm{~mm}$ (equivalent to 12 tubule radii), resulting in a ratio of close to 1 between the cell layer absorbed dose and the whole-testis absorbed dose. For radionuclides emitting $\alpha$-particles, which have short ranges, it is critical to determine precisely where in the testis there is uptake of activity to correctly calculate absorbed doses.

With few exceptions, there is little knowledge about the exact localization of radioactive agents in the testis. Because the blood-testis barrier normally prevents agents from entering the seminiferous tubule, the most probable site of radiopharmaceutical localization is the interstitial tissue. However, radiometals and some antibodies constitute an exception and are of special interest because they seem to accumulate inside the seminiferous tubule and in the spermatogonial cells $(3,4,25)$.

An absorbed dose as low as 150 mGy to spermatogonia is sufficient to cause cell death and a significant decrease in sperm count several weeks later. At this absorbed dose, fertility will be restored if a sufficient number of spermatogonial stem cells survive to repopulate the seminiferous epithelium. However, this recovery may take a considerable time. In recent years, the loss of male germ cells after exposure to ionizing radiation has been attributed to apoptosis. Liu et al. demonstrated that absorbed doses of 25-200 mGy induced a significant increase in apoptosis in both spermatogonia and spermatocytes, with a maximal effect at $75 \mathrm{mGy}(40)$.

\section{CONCLUSION}

The results show the importance of considering the possibility of nonuniform distribution of many radioactive agents in the testicular tissue and possible hot spots, which may be of importance in the estimation of radiation risks. It is therefore important that the testis be included in the evaluation of the biodistribution of radiopharmaceuticals used in preclinical trials on men.

\section{DISCLOSURE STATEMENT}

The costs of publication of this article were defrayed in part by the payment of page charges. Therefore, and solely to indicate this fact, this article is hereby marked "advertisement" in accordance with 18 USC section 1734.

\section{ACKNOWLEDGMENTS}

This research was supported by grants from the Swedish Cancer Society, the Swedish Radiation Safety Authority, the Berta Kamprad Foundation, and the Gunnar Nilsson foundation. No other potential conflict of interest relevant to this article was reported.

\section{REFERENCES}

1. Jackson C, Jackson H, Bock M, Morris ID, Sharma HL. Metal radionuclides and the testis. Int J Radiat Biol. 1991;60:851-858.

2. Hoyes KP, Cox M, Jackson C, Sharma HL, Morris ID, Hendry JH. Localization of indium-114m in the rodent testis. Int J Radiat Biol. 1992;62:381-382. Available at: http://informahealthcare.com/toc/rab/62/3. Accessed November 1, 2011.

3. Jönsson B-A, Strand S-E, Emanuelsson H, Larsson BS. Tissue, cellular, and subcellular distribution of indium radionuclides in the rat. Biophysical Aspects of Auger Processes: AAPM Symposium Series No. 8. Woodbury, NY: American Institute of Physics; 1992:249-272.

4. Nettleton JS, Lawson RS, Prescott MC, Morris ID. Uptake, localization, and dosimetry of In-111 and Tl-201 in human testes. J Nucl Med. 2004;45:138-146.

5. Shen S, Meredith R, Duan J, et al. Testicular uptake and radiation dose in patients receiving Zevalin and Pretarget CC49Fusion protein. Cancer Biother Radiopharm. 2005;20:110-118.

6. Fisher DR, Shen S, Meredith RF. MIRD dose estimate report no. 20: radiation absorbed-dose estimates for ${ }^{111} \mathrm{In}$ - and ${ }^{90}$ Y-ibritumomab tiuxetan. J Nucl Med. 2009;50:644-652.

7. Chiesa C, Botta F, Coliva A, et al. Absorbed dose and biologically effective dose in patients with high-risk non-Hodgkin's lymphoma treated with high-activity myeloablative ${ }^{90}$ Y-ibritumomab tiuxetan (Zevalin). Eur J Nucl Med Mol Imaging. 2009;36:1745-1757.

8. Rowley MJ, Leach DR, Warner GA, Heller CG. Effect of graded doses of ionizing radiation on the human testis. Radiat Res. 1974;59:665-678.

9. Nonstochastic effects of ionizing radiation: ICRP publication 41. Ann ICRP. 1984;41(3)

10. Yousif L, Blettner M, Hammer G. amp, 1 P, Zeeb H. Testicular cancer risk associated with occupational radiation exposure: a systematic literature review. J Radiol Prot. 2010;30:389-406.

11. Health Risks from Exposure to Low Levels of Ionizing Radiation: BEIR VII Phase 2. Washington, DC: BEIR; 2006.

12. International Commission on Radiological Protection (ICRP). The 2007 recommendations of the International Commission on Radiological Protection. ICRP publication 103. Ann ICRP. 2007;37(2-4).

13. Oakberg EF. Duration of spermatogenesis in the mouse and timing of stages of the cycle of the seminiferous epithelium. Am J Anat. 1956;99:507-516.

14. Meistrich ML. Critical components of testicular function and sensitivity to disruption. Biol Reprod. 1986;34:17-28.

15. Rao DV, Narra V, Howell RW, Lanka V, Sastry KSR. Induction of sperm head abnormalities by incorporated radionuclides: dependence on subcellular distribution, type of radiation, dose rate, and presence of radioprotectors. Radiat Res. 1991;125:89-97. 
16. Meistrich ML, Samuels RC. Reduction in sperm levels after testicular irradiation of the mouse: a comparison with man. Radiat Res. 1985;102:138-147.

17. Meistrich ML, Reid B, Barcellona W. Changes in sperm nuclei during spermiogenesis and epididymal maturation. Exp Cell Res. 1976;99:72-78.

18. Hendry JH. Survival of cells in mammalian tissues after low doses of irradiation: a short review. Int J Radiat Biol Relat Stud Phys Chem Med. 1988;53: 89-94.

19. Holstein AF, Schulze W, Davidoff M. Understanding spermatogenesis is a prerequisite for treatment. Reprod Biol Endocrinol. 2003;1:107.

20. International Commission on Radiological Protection (ICRP). ICRP publication 89: basic anatomical and physiological data for use in radiological protectionreference values. Ann ICRP. 2002;32(3-4).

21. Mescher AL. Junqueira's Basic Histology: Text and Atlas. 12th ed. New York, NY: McGraw Hill Medical; 2009.

22. Hoyes KP, Hendry H, Sharma M. Transferrin-mediated uptake of plutonium by spermatogenic tubules. Int J Radiat Biol. 1996;70:467-471.

23. Hoyes KP, Johnson C, Johnston RE, et al. Testicular toxicity of the transferrin binding radionuclide 114mIn in adult and neonatal rats. Reprod Toxicol. 1995;9:297-305.

24. Hoyes KP, Nettleton JS, Lawson RS, Morris ID. Transferrin-dependent uptake and dosimetry of Auger-emitting diagnostic radionuclides in human spermatozoa. J Nucl Med. 1998;39:895-899.

25. Jönsson BA. Biokinetics and localization of some In-111-radiopharmaceuticals in rats at the macroscopic and microscopic level: an approach towards small scale dosimetry [doctoral thesis]. Lund, Sweden: Lund University; 1991.

26. Jönsson B-A, Strand S-E, Larsson B. A quantitative autoradiographic study of heterogenous activity distribution for different ${ }^{111}$ In-labeled radiopharmaceuticals in rat tissues. J Nucl Med. 1992;33:1825-1833.

27. Hoyes KP, Sharma HL, Jackson H, Hendry JH, Morris ID. Spermatogenic and mutagenic damage after paternal exposure to systemic indium-114m. Radiat Res. 1994;139:185-193.

28. Beatty BG, Paxton RJ, Sheibani K, et al. Testis Imaging with In-111-labeled anticarcinoembryonic antigen monoclonal antibody: identification of carcinoembryonic antigen in normal germ cells. Cancer Res. 1986;46:6503-6508.
29. Ingvar C, Wingårdh K, Ljungberg M, Strand S, Norrgren K, Tennvall J. Quantitative biokinetics study of ${ }^{111} \mathrm{In}$-labeled $\mathrm{F}\left(\mathrm{ab}^{\prime}\right) 2$ in patients with colorectal cancer. Antibody Immunoconj Radiopharm. 1991;4:587-593.

30. Wiseman GA, Leigh BR, Erwin WD, et al. Radiation dosimetry results from a phase II trial of ibritumomab tiuxetan (Zevalin) radioimmunotherapy for patients with non-Hodgkin's lymphoma and mild thrombocytopenia. Cancer Biother Radiopharm. 2003;18:165-178.

31. Tennvall J, Fischer M, Bischof Delaloye A, et al. EANM procedure guideline for radio-immunotherapy for B-cell lymphoma with ${ }^{90}$ Y-radiolabelled ibritumomab tiuxetan (Zevalin). Eur J Nucl Med Mol Imaging. 2007;34:616-622.

32. Absorbed-dose specification in nuclear medicine (report 67). J ICRU. 2002;2: $1-110$.

33. Howell RW, Neti PV, Pinto M, Gerashchenko BI, Narra VR, Azzam EI. Challenges and progress in predicting biological responses to incorporated radioactivity. Radiat Prot Dosimetry. 2006;122:521-527.

34. Loevinger R, Berman M. A Revised Schema for Calculation of the Absorbed Dose from Biologically Distributed Radionuclides: MIRD Pamphlet No. 1, Revised. New York, NY: Society of Nuclear Medicine; 1976.

35. Snyder W, Ford M, Warner G, Scott J. "S," Absorbed Dose per Unit Cumulated Activity for Selected Radionuclides and Organs. New York, NY: Society of Nuclear Medicine; 1975.

36. X-5 Monte Carlo Team. MCNP: A General Monte Carlo N-Particle Transport Code, Version 5, Volume I-Overview and Theory. Los Alamos, NM: Los Alamos National Laboratory; 2003 (revised 2008).

37. Hendricks J. MCNPX, Version 2.6.0 Extensions LA-UR-08-2216. Los Alamos, NM: Los Alamos National Laboratory; 2008.

38. Stabin MG, da Luz LC. Decay data for internal and external dose assessment. Health Phys. 2002;83:471-475.

39. Jönsson L, Liu X, Jönsson B-A, Ljungberg M, Strand S-E. A dosimetry model for the small intestine incorporating intestinal wall activity and cross-doses. $J$ Nucl Med. 2002;43:1657-1664.

40. Liu G, Gong P, Zhao H, Wang Z, Gong S, Cai L. Effect of low-level radiation on the death of male germ cells. Radiat Res. 2006;165:379-389. 